\title{
A tematização das lutas na Educação Física Escolar: restrições e possibilidades
}

\author{
Paulo Rogério Barbosa do Nascimento* \\ Luciano de Almeida**
}

\begin{abstract}
Resumo: O tema "lutas", indicado para ser tratado pedagogicamente pela disciplina curricular de Educação Física na escola, apresenta algumas restrições. O desafio deste trabalho foi realizar uma necessária reflexão sobre o tema e efetivas intervenções no contexto escolar, para contrapô-las. Entendemos que, com essas experiências "singulares", foi possível relativizar "empecilhos" postos para o trato pedagógico desse conteúdo na escola. Reforçarmos a convicção da importância de o professor ter claro para si sob qual perspectiva teórica tratará os conteúdos para, então, lançar mão de metodologias de trabalho sintonizadas com a teoria.
\end{abstract}

Palavras-chave: Luta. Educação Física. Currículo.

\section{INTRODUÇÃO}

Este texto objetiva participar do debate e, principalmente, instigar a construção de um corpo de conhecimentos significativos, relacionados ao trato do conteúdo de lutas, pela disciplina curricular de Educação Física na escola, assim como procura atestar a validade do diálogo entre profissionais, a troca de experiências e, ainda, a construção coletiva de novos subsídios teórico-práticos, que signifiquem e re-signifiquem tratos com os conteúdos da Educação Física escolar.

No momento, podemos afirmar que alguns dos argumentos em relação ao tema na Educação Física escolar, que perpassam o posicionamento e as concepções dos professores atuantes em

Mestre em Educação nas Ciências (UNIJUÍ). Professor do Curso de Educação Física da URI (Campus Santo Ângelo) e Professor da Escola Municipal Madalena, Panambi, RS, Brasil. E-mail: paulonascimento@urisan.tche.br

"* Mestre em Educação nas Ciências (UNIJUÍ). Professor do Curso de Educação Física da URI (Campus Santo Ângelo) e Professor da Escola Estadual de Ensino Médio Santo Augusto, Santo Augusto, RS, Brasil. E-mail: lucianoedf@urisan.tche.br 
escolas, são restritivos para a efetivação do trato pedagógico desse conteúdo. Diante disso, buscamos refletir sobre a temática e realizar intervenções pedagógicas no âmbito escolar, capazes de suscitar elementos para nos posicionarmos mais categoricamente, inclusive considerando a possibilidade de contrapor algumas supostas restrições.

As reflexões e intervenções que seguem originaram-se a partir do diálogo e interesse comum dos autores do texto. De um lado, um professor de Educação Física sem vivências específicas em alguma modalidade de luta e, de outro, um com vivência profissional no ensino da capoeira.

\section{ARGUMENTOS RESTRITIVOS EM RELAÇÃO AO TRATO DA LUTA NA DISCIPLINA DE EDUCAÇÃO FÍSICA}

A ampliação dos temas ou conteúdos a serem devidamente estudados na disciplina de Educação Física na escola, fruto, também, de mudanças paradigmáticas ${ }^{1}$ no próprio campo é fato, porém, a efetivação de tal ampliação não é um processo que ocorre rapidamente.

No espaço de intervenção escolar, podemos afirmar que o tema/ conteúdo de lutas é pouco acessado e, inclusive, o seu trato pedagógico suscita questionamentos e preocupações diversas por parte dos profissionais atuantes na Educação Física.

Se o fenômeno lutas aparece na escola, conforme Nascimento (2005), isso acontece pelas aberturas preconizadas por essa instituição para terceiros realizarem, em seu espaço, oficinas, voluntárias ou não, desvinculadas da disciplina de Educação Física e do projeto político-pedagógico da Escola.

Em pesquisa realizada pelos alunos do curso de graduação em Educação Física da UNIJUÍ, Campi Ijuí e Santa Rosa (RS), e da ${ }^{1}$ Considera-se, para este estudo, a mudança paradigmática que se refere à introdução do
conceito de "cultura" nos estudos acadêmicos da área de Educação Física, o que tem
ampliado a visão da área para além do corpo eminentemente biológico, mas também histórico,
social e cultural.

Movimento, Porto Alegre, v. 13, n. 03, p. 91-110, setembro/dezembro de 2007. 
URI/Santo Ângelo (RS), na disciplina de Metodologia do Ensino de Lutas desenvolvida no $1^{\circ}$ semestre de 2006, segundo Nascimento (2007, p. 3): ${ }^{2}$

[...] buscou verificar as concepções dos professores de Educação Física sobre o conteúdo de lutas a ser tratado pela disciplina de Educação Física, intervenções já realizadas e, como acreditam que este tema deve ser tratado por esse componente curricular $[\ldots]$

foram encontrados indicadores que se mostraram argumentos restritivos para a possibilidade de trato pedagógico desse tema/ conteúdo. Entre outros argumentos restritivos verificados, destacase, basicamente, dois dos mais recorrentes nas respostas obtidas: ${ }^{3}$

1) a falta de vivência pessoal em lutas por parte dos professores, tanto no cotidiano de vida, como no âmbito acadêmico;

2) a preocupação com o fator violência, que julgam ser intrínseco às práticas de luta, o que incompatibiliza a possibilidade de abordagem deste conteúdo na escola.

\section{PERSPECTIVAS TEÓRICO-METODOLÓGICAS OU CAMINHOS QUE PERPASSARAM O ESTUDO PROPOSTO}

Compreende-se que o trato pedagógico do componente lutas na Educação Física escolar deva comportar necessariamente aspectos da autonomia, criticidade, emancipação e a construção de conhecimentos significativos. As reflexões que apontam para a cultura corporal de movimento como o conjunto de conhecimentos que devem ser "tematizados" pela Educação Física podem municiar, pedagogicamente, para construir possibilidades metodológicas para o trato específico deste tema.

\footnotetext{
${ }^{2}$ NASCIMENTO, Paulo R. B. Sistematização do tema/conteúdo de lutas para a Educação Física escolar. 2007. (Mímeo).

${ }^{3}$ No estudo citado, a falta de sistematização deste tema/conteúdo também foi uma indicação relevante por parte dos professores, sendo então tratado, especificamente, por Nascimento em outro artigo, intitulado "Sistematização do tema/conteúdo de Lutas para a Educação Física Escolar", em vias de publicação.

Movimento, Porto Alegre, v. 13, n. 03, p. 91-110, setembro/dezembro de 2007.
} 


\section{Antigor Originais Paulo do Nascimento e Luciano de Almeida}

Assim pensando, assumimos o desafio de realizar intervenções no âmbito da escola, tratando pedagogicamente o tema/conteúdo de lutas na Educação Física, considerando a perspectiva acima citada, a formação e/ou vivências de cada um dos professores e os contextos escolares diferenciados onde cada um atua.

Este trabalho, que inicialmente surgiu de discussões entre os pesquisadores sobre os limites e as possibilidades de se trabalhar com o tema/conteúdo lutas na escola, evoluiu para a idéia de realizar intervenções nas escolas em que atuávamos e, depois, foi tomando corpo em nossos diálogos e encontros em que discutíamos acerca da sistematização de nossas aulas.

Nesse sentido, adotamos como metodologia a pesquisa-ação, ${ }^{4}$ por articular o objetivo prático, que visa buscar um diagnóstico da realidade investigada, na tentativa de encontrar soluções alcançáveis para as situações consideradas problemas, a fim de transformá-las, ${ }^{5}$ com o objetivo de "[...] obter informações que seriam de difícil acesso por meio de outros procedimentos, aumentar nosso conhecimento de determinadas situações (reivindicações, representações, capacidades de ação ou de mobilização, etc.)" (THIOLLENT, 1988, p. 18).

Não dar um tratamento pedagógico ao tema é, para nós, um problema e, por isso, nos desafiamos a tematizar este conteúdo nas diferentes realidades em que atuamos. Um dos pesquisadores, sem vivência pessoal em lutas no seu cotidiano de vida e também acadêmico, desafiou-se a tratar pela primeira vez deste tema, de forma sistematizada, e outro, com vivência pessoal na prática e ensino da capoeira, desafiou-se a confrontar o argumento da violência como aspecto restritivo à tematização deste conteúdo no âmbito escolar.

O fruto do trabalho é apresentado a seguir em forma de relato, ${ }^{6}$ procurando deixar claro sob qual entendimento de Educação Física e qual perspectiva de trato do conteúdo o mesmo foi desenvolvido.

\footnotetext{
${ }^{4}$ É preciso chamar a atenção para o fato de que adotamos a pesquisa-ação como metodologia de referência, sem fechar as portas para elementos que escapem desse universo, por entendermos que isso poderia obstruir nosso percurso investigativo.

${ }^{5}$ Assim, precisamos nos reconhecer como professores-pesquisadores, que criam e recriam a sua profissão no contexto da prática (MALDANER, 2000).

${ }^{6} \mathrm{O}$ relato $\mathrm{n}^{\circ} 1$ refere-se à intervenção realizada pelo professor Luciano de Almeida. O relato $n^{\circ} 2$, à intervenção realizada pelo professor Paulo Rogério Barbosa do Nascimento.
}

Movimento, Porto Alegre, v. 13, n. 03, p. 91-110, setembro/dezembro de 2007. 
Acreditamos, desta forma, poder contrapor os argumentos restritivos citados, inserindo-nos no debate sobre a temática e contribuindo para a superação de pseudo-entraves ao oferecimento e desenvolvimento deste tema no ensino escolar formal.

\section{RELATOS E ANÁLISES}

\subsection{RELATO NO 1: A NECESSIDADE DE O PRO- FESSOR SER ESPECIALISTA OU TER VIVÊNCIAS SUBSTANCIAIS EM "LUTAS": UM DISCUTÍVEL ARGUMENTO RESTRITIVO PARA O TRATO DO TEMA NA EDUCAÇÃO FÍSICA ESCOLAR}

Deteremos o foco de nossa análise no relato que buscou contrapor o argumento de que o professor, para desenvolver o conteúdo de lutas na Educação Física escolar, precisa, necessariamente, ter tido vivências de lutas no seu cotidiano de vida, ou ser um especialista em alguma modalidade de luta. Será que esse requisito é um critério necessariamente indispensável?

A resposta a essa pergunta não pretende ser universal, mas objetiva contribuir para a reflexão dos professores que estão inseridos nas escolas e que se sentem "despreparados" em tratar este tema, de certa forma, "novo" na escola. Esta primeira resposta vem em forma de relato de uma experiência que apresenta os limites e possibilidades de uma intervenção com uma turma de $5^{a}$ série de uma escola da rede pública estadual da cidade de Santo Augusto (RS).

Neste relato, apresentamos uma abordagem que não deve ser considerada uma "receita" para o trabalho do ensino de lutas na Educação Física escolar, e sim apenas uma das possibilidades do trato pedagógico do tema, uma vez que qualquer proposta, ao ser universalizada sem considerar o contexto no qual se insere, está condenada ao fracasso.

Nas aulas de Educação Física, tem-se dado prioridade ao plano procedimental (emprego de técnicas e fundamentos), enquanto tem-se

Movimento, Porto Alegre, v. 13, n. 03, p. 91-110, setembro/dezembro de 2007. 
deixado de lado o atitudinal (valores nas e para as práticas), bem como o conceitual (entendimento do porquê realizar este ou aquele movimento) (DARIDO, 2001).

Nossa intervenção está alicerçada nessas três dimensões e nas seguintes questões, que nos deram um indicativo de como constituir o processo de ensino de lutas no contexto escolar: ${ }^{7}$ por quê ensinar? (justificativa); o que ensinar? (seleção de conteúdos); quando ensinar? (etapas ensino-aprendizagem); como ensinar? (metodologia); o que, para que, como e quando avaliar? (construção de um processo de avaliação).

Da tentativa de esboçar um entendimento acerca destas questões, consolidou-se a presente intervenção. Nesse sentido, abordamos o tema, no plano conceitual, com base nos Parâmetros Curriculares Nacionais (PCNs), que caracterizam os esportes de combate/luta como "[...] disputas em que o(s) oponente(s) deve(m) ser subjugado(s), mediante técnicas e estratégias de desequilíbrio, contusão, imobilização ou exclusão de um determinado espaço na combinação de ações de ataque e defesa" (BRASIL, 1997, p. 49).

A partir da explicitação desse conceito, iniciamos nossa discussão com os alunos para que eles expusessem as lutas que "conheciam". Em suas falas, surgiram: judô, karatê, boxe, kung fu, sumô, etc. Algumas lutas eles não sabiam nomear, mas deram algumas características para que pudéssemos identificá-las conjuntamente. Após, elegemos as lutas que utilizam como técnicas, táticas e estratégias de oposição, a imobilização, a exclusão de determinado espaço e o desequilíbrio, ou seja, a greco-romana, o sumô e o judô.

Abordamos o esporte de combate/luta institucionalizado, no plano conceitual, para que os alunos pudessem se apropriar dos elementos que constituem as lutas, como histórico, rituais, crenças e principais regras, através de trabalho de pesquisa. Outro recurso utilizado para que os alunos compreendessem este tema foi a visualização e análise de vídeos das três modalidades estudadas.

A abordagem do esporte institucionalizado permite aos alunos aprofundarem seus conhecimentos sobre os esportes de combate/

\footnotetext{
${ }^{7}$ Essas questões embasam também uma proposta de intervenção que vem sendo realizada, desde 2004, na escola em que parte deste estudo vem sendo desenvolvido (ALMEIDA; FENSTERSEIFER, 2006).
}

Movimento, Porto Alegre, v. 13, n. 03, p. 91-110, setembro/dezembro de 2007. 
lutas, tendo em vista que o acesso aos mesmos é superficial e carrega uma grande dose de preconceito, atribuindo-lhes o imaginário de esportes violentos.

No plano procedimental, a ênfase recai sobre os jogos de lutas (NASCIMENTO, 2006), ${ }^{8} \mathrm{com}$ a conseqüente transformação pedagógica desses esportes (KUNZ, 2001). Dos jogos de lutas realizados em aula, destacamos o cabo de guerra, briga de galo, exclusão de espaço com ombro, mãos, conquista da quadra do oponente e conquista de objetos com oposição. Alguns elementos do esporte são incorporados nos jogos de lutas com a criação de regras e novos jogos propostos pelos alunos. Utilizamo-nos de três exemplos de jogos de lutas propostos por três grupos de alunos. ${ }^{9}$

\begin{tabular}{|c|c|c|c|c|}
\hline $\begin{array}{l}\text { Nome } \\
\text { da luta }\end{array}$ & $\begin{array}{c}\text { Modo de } \\
\text { jogar/objetivo }\end{array}$ & Regras & Proibições & Estratégias \\
\hline $\begin{array}{l}\text { Jogo de } \\
\text { costas }\end{array}$ & $\begin{array}{l}\text { Derrotar o } \\
\text { adversário, tirando-o } \\
\text { da pista, só usando } \\
\text { as costas. }\end{array}$ & $\begin{array}{l}\text { Tirar o } \\
\text { adversário } \\
\text { da pista; } \\
\text { usando só } \\
\text { as costas, } \\
\text { dando as } \\
\text { mãos } \\
\text { para o } \\
\text { adversário } \\
\text { não cair. }\end{array}$ & $\begin{array}{l}\text { É proibido } \\
\text { soltar as } \\
\text { mãos e } \\
\text { qualquer } \\
\text { tipo de } \\
\text { violência } \\
\text { com os pés. }\end{array}$ & $\begin{array}{l}\text { Exclusão do } \\
\text { espaço. }\end{array}$ \\
\hline $\begin{array}{l}\text { Luta } \\
\text { gaúcha }\end{array}$ & $\begin{array}{l}\text { Vestir-se de gaúcho; } \\
\text { desequilibrar o } \\
\text { adversário no } \\
\text { espaço adaptado, } \\
\text { com um dos braços } \\
\text { nas costas e o outro } \\
\text { tentando } \\
\text { desequilibrar o } \\
\text { adversário. }\end{array}$ & $\begin{array}{l}\text { Conseguir } \\
\text { tirar o } \\
\text { adversário } \\
\text { do espaço, } \\
\text { não tirando } \\
\text { um dos } \\
\text { braços de } \\
\text { trás das } \\
\text { costas. }\end{array}$ & $\begin{array}{l}\text { É proibido } \\
\text { trocar de } \\
\text { braço } \\
\text { quando } \\
\text { estiver } \\
\text { jogando e } \\
\text { não pode } \\
\text { usar } \\
\text { qualquer } \\
\text { tipo de } \\
\text { violência } \\
\text { com os pés. }\end{array}$ & $\begin{array}{l}\text { Exclusão do } \\
\text { espaço. }\end{array}$ \\
\hline
\end{tabular}

${ }^{8}$ NASCIMENTO, Paulo R. B. Apostila da disciplina de Metodologia do Ensino de lutas, 2006. (Mímeo).

${ }^{9}$ Será mantida a descrição original dos alunos, sem alteração ou correção de erros ortográficos e/ou gramaticais.

Movimento, Porto Alegre, v. 13, n. 03, p. 91-110, setembro/dezembro de 2007. 


continuação.
\begin{tabular}{|l|l|l|l|l|}
\hline \multicolumn{1}{|c|}{} & $\begin{array}{l}\text { Os oponentes desta } \\
\text { luta devem ficar de } \\
\text { joelhos em um lugar } \\
\text { apropriado e têm } \\
\text { joelhos }\end{array}$ & $\begin{array}{l}\text { Permanecer } \\
\text { que tentar derubar o } \\
\text { outro. Quem ficar } \\
\text { com os } \\
\text { com joelhos no } \\
\text { joelhos no } \\
\text { chão ganha a luta. } \\
\text { Quem tirar, perde. }\end{array}$ & $\begin{array}{l}\text { chão. } \\
\text { soltar as } \\
\text { mãos. É } \\
\text { proibido dar } \\
\text { socos nos } \\
\text { adversários. }\end{array}$ & Desequilíbrio. \\
\end{tabular}

Quadro 1. Lutas propostas pelos alunos

Neste quadro, percebemos a intenção de prevenir atitudes de deslealdade dos alunos através das proibições contidas em seus jogos, para demonstrar o respeito à ética, ao esporte e inibição da violência (dimensão atitudinal) nos jogos criados/adaptados por eles mesmos.

Todos os grupos realizaram os jogos de lutas elaborados pelos colegas e apontaram alguns elementos que poderiam ser alterados, ou melhor explicitados, através da inclusão de novas regras, proibições, formas de pontuar, etc. Nestes jogos, surgiram vários elementos para serem discutidos no plano atitudinal, como respeito às regras, à integridade física e moral dos colegas e às diferenças de gênero, estatura e peso.

Para exemplificar, trazemos para a discussão um diálogo estabelecido entre professor e aluno ao final de uma das aulas: ${ }^{10}$

Aluno: Professor, até que eu tô gostando das aulas de lutas, mas por quê eu tenho que lutar sempre com o João? ${ }^{11}$

Professor: Gabriel, como foram tuas experiências com os jogos de lutas nas primeiras aulas, quando

\footnotetext{
${ }^{10}$ Fizemos um relato após a aula para não perdermos informações relevantes para o nosso trabalho diário.

${ }^{11}$ Adotamos nomes fictícios para preservar as identidades dos alunos.
}

Movimento, Porto Alegre, v. 13, n. 03, p. 91-110, setembro/dezembro de 2007. 
você disputava com as meninas e com meninos mais baixos e de peso inferior?

Aluno: Sempre ganhei.

Professor: E quando você luta com o João?

Aluno: Ganho quase sempre, mas com maior dificuldade.

Professor: Por quê se joga/luta?

Aluno: Para tentar ganhar.

Professor: Pois é, a incerteza do resultado é o que dá prazer ao jogo. Você não acha?

Aluno: Acho que sim.

Professor: Você acha que teus colegas gostam de perder os jogos/lutas para você?

Aluno: Acho que não, mas perder faz parte do jogo, não é?

Professor: Com certeza, mas perder sempre, é legal? Aluno: Não.

Professor: Vamos pensar no seguinte: nos jogos de lutas você vem levando vantagem, pois este exige força (jogos de exclusão do espaço), mas em outros jogos, você nem sempre se sai muito bem, não é?

Aluno: É verdade.

Professor: É necessário ganhar sempre?

Aluno: Não.

Professor: Você gosta de perder sempre?

Aluno: Não.

Neste diálogo estabelecido com Gabriel, tentamos pontuar questões relacionadas com ganhar e perder, gênero, estatura e peso. Gabriel faz parte da turma dos "gordinhos" que, nos jogos esportivos, como o futsal, por exemplo, vai para o gol, é o último a ser escolhido para fazer parte de uma equipe ou, ainda, ninguém o escolhe. Nos jogos de lutas, lhe são proporcionadas vivências de sucesso, pois ganha a maioria das lutas das quais participa. Por outro lado, faz-se

Movimento, Porto Alegre, v. 13, n. 03, p. 91-110, setembro/dezembro de 2007. 
necessário que ele reflita sobre as vivências de fracasso e de sucesso, pois teve a oportunidade de vivenciar essas duas experiências. Quais são as que mais nos marcam? É preciso estabelecer uma relação equilibrada entre esses dois extremos, para que os alunos adotem critérios para saber analisar, avaliar e criticar situações de inclusão e exclusão nas aulas de Educação Física, contribuindo, desta forma, para a construção do respeito às diversidades e individualidades dos sujeitos que fazem parte de cada contexto (plano atitudinal).

Conseguimos dar novos sentidos a alguns preconceitos que os alunos tinham com relação às lutas, como, por exemplo, no sumô, o imaginário dos alunos era de que somente pessoas muito pesadas e grandes pudessem praticar esta luta, e geralmente é isso que ocorre no esporte institucionalizado. Porém, quando adaptamos as regras e damos um trato pedagógico a elas, podemos dar novos sentidos e produzir conhecimento e oportunizar diferentes vivências aos alunos, fato que se confirma no depoimento da aluna Laís: "Sumô: é uma luta que pode ser praticada por qualquer pessoa; o objetivo é tirar o outro jogador do lugar marcado e aí pontua."

Essa intervenção nos possibilitou confirmar a tese de que não há necessidade de termos uma especialização em uma modalidade de lutas, desde que nosso objetivo não esteja pautado na formação de atletas/lutadores, mas na produção de conhecimento nas aulas de Educação Física. Isso não quer dizer que devamos desconsiderar as contribuições dos especialistas que dedicam seus estudos a este tema. Necessitamos da reflexão coletiva entre especialistas e nãoespecialistas para produzirmos propostas bem fundamentadas e, com isso, sistematizar novas intervenções que irão contribuir em nossa prática pedagógica e, de certa forma, evitar o distanciamento com o tema.

\subsection{RELATO NO 2: "VIOLÊNCIA": OUTRO DISCUTÍVEL ARGUMENTO RESTRITIVO PARA O TRATO DO TEMA DE LUTAS NA EDUCAÇÃO FÍSICA ESCOLAR}

A violência é vista, conforme foi possível interpretar a partir das falas dos professores entrevistados, como algo intrínseco às

Movimento, Porto Alegre, v. 13, n. 03, p. 91-110, setembro/dezembro de 2007. 
práticas da luta, e que pode aflorar e/ou despertar ainda mais se o tema for tratado na escola, pois muitos alunos já demonstram traços de comportamento violento no cotidiano escolar.

A violência, bem sabemos, é uma característica presente na sociedade como um todo e, neste caso, a escola não fica imune a ela. Ademais, comportamentos mais ou menos agressivos também se fazem notar nas aulas de Educação Física.

Partindo dessas constatações, a questão que colocamos é: o trato do tema/conteúdo de lutas realmente contribuiria para suscitar comportamentos violentos e, por conseguinte, indesejáveis no contexto da escola e da disciplina de Educação Física?

Olivier (2000, p. 11), ao referir-se à violência, entende-a como: [...] inerente às relações sociais", e a concebe como "[...] modos de expressão e de comunicação", que surgem em situações de conflito, de ameaças, de incerteza. O autor posiciona-se no sentido de que as atividades de luta na escola, sistematizadas e metodologicamente pensadas e conduzidas, servem como importantes elementos de estruturação motora, psico-afetiva e social, que ajudam "[...] a criança a gerir e a controlar a complexidade das relações violentas no interior do grupo social".

Ao referir-se à questão "Violência e Mídia", Olivier (2000, p. 13) reconhece a exposição extrema das crianças à imagens violentas, através de heróis lutadores e, mesmo sem avançar na análise dessa questão na ótica de ser "nociva" ou não, entende estarmos diante de um fator que não deve ser negligenciado quanto à formação de nossas crianças. Assim, o autor reconhece a escola como possível detentora de um papel de "contra poder", uma vez que pode privilegiar cada vez mais a "comunicação, as trocas no contexto de suas próprias regras sociais".

Percebemos pelas observações cotidianas e por denúncias de autores da área da Educação Física, que em muitas realidades escolares há o predomínio de uma "monocultura", se considerarmos a diversidade de práticas da cultura corporal de movimento, e que essa monocultura se materializa, invariavelmente, com fomento apenas do "jogar futebol". Dessa forma, poderíamos nos perguntar

Movimento, Porto Alegre, v. 13, n. 03, p. 91-110, setembro/dezembro de 2007. 


\section{Antigos Originais Paulo do Nascimento e Luciano de Almeida}

se, nas práticas mais fomentadas na escola, o aspecto violência, então, não se manifesta?

Uma constatação no campo empírico, que se deu através da prática cotidiana, foi de que o "jogar futebol" condensa sim uma série de atitudes que poderíamos considerar violentas e perigosas. Violência essa que se manifesta tanto nas jogadas ríspidas e malintencionadas, como no aspecto verbal.

Outra questão interessante é de que a segunda-feira é o dia da semana em que os alunos que estão, de certa forma acostumados com uma prática monocultural da Educação Física, se tornam ainda mais afoitos para "jogar futebol"12 livremente. Neste caso, conforme as leis que vão se estabelecendo no grupo, sem a necessária eqüidade capaz de conferir àquele momento certo equilíbrio de forças entre os grupos constituídos e, muito menos, uma maior inserção dos menos habilidosos para jogar, os quais cumprem apenas a função de completar as equipes, quando não são literalmente excluídos.

Outra característica que fica evidente na situação explicitada é de que podemos constatar, nas atitudes dos alunos durante o jogo de futebol, um trailer dos comportamentos vividos, percebidos, assistidos, no final de semana. Este contato, para uns, começa no sábado com o jogo da escolinha à qual pertencem, após o jogo de seu pai, amigo ou parente, no futebol de várzea, ${ }^{13}$ continua no campinho ou quadra perto de sua casa e recomeça no domingo com os programas esportivos da manhã na televisão. Esses cumprem o papel de incentivar e garantir o espectador para os diversos jogos e campeonatos simultâneos que estarão ocorrendo à tarde e, claro,

\footnotetext{
${ }^{12}$ Não é pretensão nos posicionarmos contra o futebol, mas sim utilizá-lo como exemplo palpável da nossa realidade escolar, para então realizarmos um contraponto, pensando as lutas como conteúdo da Educação Física. Entendemos ser pertinente esta exemplificação, uma vez que o futebol é prática "naturalizada na escola", mas apresenta contradições significativas, tanto na forma como é tratado "pedagogicamente" na escola, quanto na forma como se apresenta no campo social mais amplo, o que também pode ser dito em relação às lutas.

${ }^{13}$ Expressão popular que designa as incontáveis partidas de futebol do âmbito não profissional que, amistosas ou não, com maior ou menor grau de organização, com maior ou menor grau de interferência do poder público, acontecem no cotidiano das cidades e vilarejos, ocupando os mais diversos tipos de campos e gramados, sendo os finais de semana os períodos mais expressivos em que são realizadas.
}

Movimento, Porto Alegre, v. 13, n. 03, p. 91-110, setembro/dezembro de 2007. 
sendo transmitidos ao vivo, retornando à noite com as intermináveis reprises de gols e melhores lances, exaltação dos "craques" do momento e debates polêmicos acerca dos jogos que continuarão nos telejornais e programas da segunda-feira.

Frente a essa exposição extrema dos alunos, a carga emocional protagonizada pela indústria do futebol em todas as suas escalas, percebe-se, no campo ou quadra da escola, especialmente no dia de segunda-feira, como já referido, a imitação dos "craques" do momento, mas também da agressividade do jogo, expressa na rispidez das entradas, nos gestos agressivos e, principalmente, nas falas com tons e significados ofensivos e agressivos e carregadas das gírias dos gramados.

Para além desta análise realizada, também observamos o comportamento agressivo de colegas, pais e professores, à beira das quadras e campos esportivos, o que nos levou a pensar que há certo tipo de emanação da violência que está perfeitamente se instaurando como natural, justificável, inclusive no âmbito da escola.

A partir dos elementos desta análise, cabe-nos perguntar, novamente, se a abordagem da luta no âmbito escolar contribuiria para fazer aflorar comportamentos agressivos e trazer, inclusive, transtornos para o próprio professor poder interagir com seu grupo de alunos, inviabilizando assim o trabalho a ser realizado?

Com base nestas observações e questionamentos, realizamos uma intervenção numa turma de $4^{a}$ série do ensino fundamental, que vinha apresentando um grau elevado de dificuldade para manejarem suas emoções, o que estava sistematicamente gerando comportamentos agressivos exagerados, física e verbalmente, principalmente quando as práticas realizadas envolviam competição coletiva.

A intervenção teve o intuito de estudar e vivenciar as atividades de luta com os alunos, buscando construir coletivamente a prática e possibilitando a interação entre os mesmos, de uma maneira diferenciada dos jogos coletivos com bola, cuja lógica comporta a oposição e colaboração, para ofertar a vivência da oposição com contato corporal característico das lutas.

Para tanto, essa perspectiva de vivência, intencionalmente mediada pelo professor, foi adotada no sentido conferido por Sbórquia

Movimento, Porto Alegre, v. 13, n. 03, p. 91-110, setembro/dezembro de 2007. 


\title{
104 Astifos Orifinais Paulo do Nascimento e Luciano de Almeida
}

e Gallardo (2006, p. 1): "[...] de pôr os alunos em contato com a cultura corporal, partindo do pressuposto de que a cultura é um patrimônio universal ao qual todo ser humano deveria ter direito"; ofertar essas vivências significa que:

[...] o interesse pedagógico não está centrado no domínio técnico dos conteúdos, mas no seu domínio conceitual, na perspectiva de um saber sistematizado que supere o senso comum, inserido num espaço humano de convivência, em que possam ser vivificados aqueles valores humanos que aumentem o grau de confiança e de respeito entre os integrantes do grupo. (SBÓRQUIA; GALLARDO, 2006, p. 1).

A seguir, apresentamos um relato resumido da vivência realizada, acompanhado de considerações gerais a respeito de cada aula desenvolvida e que fizeram parte do desenvolvimento e avaliação contínua de todo o processo:

\begin{tabular}{|c|l|l|}
\hline Aula & \multicolumn{1}{|c|}{ Desenvolvimento } & Impressões gerais do professor \\
\hline 1 ạa & $\begin{array}{l}\text { Exploração, com os alunos, do texto } \\
\text { denominado "Brincando de Luar"14 } \\
\text { contendo exploração sócio-histórica } \\
\text { sobre as manifestações de luta e } \\
\text { exploração conceitual da lógica das } \\
\text { distintas lutas. Utilizou-se } \\
\text { primeiramente o texto seguido de } \\
\text { debate e visualização através do } \\
\text { vídeo de lutas diferenciadas entre si. }\end{array}$ & $\begin{array}{l}\text { Participação efetiva de todos os alunos } \\
\text { e muita expectativa inicial, o que se } \\
\text { manteve durante a aula e para a aula } \\
\text { seguinte através de tarefa levada para } \\
\text { casa de pensar sobre questões } \\
\text { estruturais de uma luta para ser } \\
\text { vivenciada, conforme critérios prévios } \\
\text { repassados aos alunos, quanto ao } \\
\text { objetivo, ações permitidas, ações } \\
\text { proibidas, etc. }\end{array}$ \\
\hline
\end{tabular}

continua...

\begin{abstract}
${ }^{14} \mathrm{O}$ texto, elaborado pelo professor responsável pela intervenção, tratou de conhecimentos sócio-históricos gerais a respeito das lutas, com a preocupação de adotar uma linguagem acessível à turma, conforme sua série e contexto, por exemplo: houve, inclusive, referência aos animais (gato, cachorro, etc.), e suas reações, que podemos classificar como brincar de luta. Essa linguagem foi ao encontro da realidade sociocultural dos alunos, que pertencem a uma comunidade da zona rural, o que despertou os mais diversos relatos e exemplos, baseados nas suas experiências de vida. O escrever, reescrever, adequar, exemplificar numa linguagem acessível aos contextos socioculturais e níveis de compreensão, das turmas escolares e/ou dos escolares de cada realidade específica, conceitos, idéias, conhecimentos, que como profissionais acessamos numa linguagem técnica, nos parece cada vez mais uma habilidade necessária do professor de Educação Física, o que definitivamente redimensiona seu papel "estereotipado" de "instrutor de ginástica", apenas.
\end{abstract}

Movimento, Porto Alegre, v. 13, n. 03, p. 91-110, setembro/dezembro de 2007. 


\begin{tabular}{|c|c|c|}
\hline $2^{\underline{a}}$ & $\begin{array}{l}\text { A partir do que os alunos haviam } \\
\text { pensado como tarefa de casa, } \\
\text { estabelecemos em aula a criação } \\
\text { coletiva de uma luta para a turma } \\
\text { vivenciar. Inicialmente, foi } \\
\text { coletivamente definida que a } \\
\text { lógica a ser vivenciada seria a de } \\
\text { levar o oponente ao chão. } \\
\text { Conforme roteiro organizado pelo } \\
\text { professor, a turma foi opinando e } \\
\text { estruturando a luta. Estavam em } \\
\text { jogo questões como local de } \\
\text { prática, ações permitidas e } \\
\text { ações não permitidas, etapas de } \\
\text { duração, posicionamento inicial, } \\
\text { ritual de início e término, normas } \\
\text { de segurança. }\end{array}$ & $\begin{array}{l}\text { Todos opinaram e, nas divergências, } \\
\text { se buscava acordo ou se fazia } \\
\text { votação, }{ }^{15} \text { processo muito bem } \\
\text { entendido, desenvolvido e } \\
\text { acompanhado pelos alunos, é claro, } \\
\text { com aquele "barulho" característico, e } \\
\text { a necessidade de intervenções do } \\
\text { professor no sentido de retornar ao } \\
\text { foco específico do trabalho em alguns } \\
\text { momentos. De início, foi necessário } \\
\text { controlar os alunos mais "afoitos", que } \\
\text { já queriam ir logo para a ação, sem } \\
\text { muito "papo", o que já era esperado. }\end{array}$ \\
\hline $3^{a}$ & $\begin{array}{l}\text { Vivência da luta elaborada pela } \\
\text { turma. }\end{array}$ & $\begin{array}{l}\text { Os alunos mantinham o entusiasmo. A } \\
\text { questão era saber se, no momento da } \\
\text { vivência, a dificuldade de manejo das } \\
\text { emoções, que muitos alunos vinham } \\
\text { demonstrando nos jogos coletivos } \\
\text { com bola, iria novamente se } \\
\text { caracterizar. A prática foi realizada } \\
\text { em cima de um único colchão, com } \\
\text { uma dupla de cada vez. Como era } \\
\text { uma primeira experiência com a } \\
\text { turma, a restrição do tempo de } \\
\text { prática devido a esse tipo de } \\
\text { organização não foi encarada } \\
\text { inicialmente pelo professor e pelos } \\
\text { alunos como um problema, e sim } \\
\text { como um momento de "testar" a } \\
\text { criação coletiva e readequá-la se } \\
\text { necessário. Alguns poucos alunos não } \\
\text { se sentiram à vontade para os } \\
\text { enfrentamentos diante dos olhos dos } \\
\text { outros e participaram apenas como } \\
\text { assistentes para opinar na avaliação } \\
\text { da tarefa. }\end{array}$ \\
\hline
\end{tabular}

continua...

\begin{abstract}
${ }^{15}$ Esta habilidade de mediar diferentes e/ou divergentes opiniões pelo uso do debate e do voto, relacionados com o conhecimento que está sendo tratado, também se entende como cada vez mais necessária, e mais que isso, uma imposição, uma vez que o professor de Educação Física passa também a ser investido do papel de "tematizador" de assuntos, temas, práticas que extrapolam a sua relação/dependência exclusiva dos conhecimentos anátomo-fisiológicos.
\end{abstract}

Movimento, Porto Alegre, v. 13, n. 03, p. 91-110, setembro/dezembro de 2007. 
continuação.

\begin{tabular}{|c|c|c|}
\hline $4^{a}$ & $\begin{array}{l}\text { Nova vivência da luta elaborada } \\
\text { pela turma, com as devidas } \\
\text { readequações percebidas e } \\
\text { opinadas pelos alunos na aula } \\
\text { anterior. }\end{array}$ & $\begin{array}{l}\text { Passada a primeira vivência, passou-se a } \\
\text { utilizar dois colchões e dividimos a turma } \\
\text { em duas, aumentando assim o tempo de } \\
\text { prática. Os alunos realizaram nova vivência, } \\
\text { que, por sugestão do professor, devia } \\
\text { contemplar enfrentamentos com colegas } \\
\text { diferentes a cada vez. Sugestão essa que } \\
\text { causou certo furor, em relação às diferenças } \\
\text { de peso, estatura, força, preferências de } \\
\text { amizades. Essas questões foram discutidas } \\
\text { permanecendo como tarefa para a turma } \\
\text { descobrir como poderíamos possibilitar que } \\
\text { uma mesma pessoa enfrentasse colegas } \\
\text { com características diferentes, sem que } \\
\text { ambas ficassem em desvantagem extrema. }\end{array}$ \\
\hline $5^{\underline{a}}$ & $\begin{array}{l}\text { Nova vivência da luta elaborada, } \\
\text { porém com mais colchões e } \\
\text { alunos dispostos em duplas, } \\
\text { todos lutando ao mesmo tempo } \\
\text { e trocando de dupla a cada nova } \\
\text { luta. }\end{array}$ & $\begin{array}{l}\text { Discutiu-se sobre as questões emanadas } \\
\text { na aula anterior e, de certa forma, houve } \\
\text { novamente resistências para maior } \\
\text { integração da turma na diversificação dos } \\
\text { enfrentamentos. O professor sugeriu então a } \\
\text { organização da aula, que visava assim } \\
\text { possibilitar aos poucos as trocas de } \\
\text { adversários, sem forçar essa atitude. Como } \\
\text { os colchonetes eram menores, adaptou-se } \\
\text { a luta para ocorrer com os alunos na } \\
\text { posição de joelhos, para não correrem o } \\
\text { risco de uma queda a partir da posição de } \\
\text { pé. Com essa organização, houve maior } \\
\text { integração da turma e maior número de } \\
\text { enfrentamentos com adversários diferentes. }\end{array}$ \\
\hline $6^{\underline{a}}$ & $\begin{array}{l}\text { Alunos dispostos em grupos de } \\
\text { quatro componentes. Vivência } \\
\text { da luta adaptada para a posição } \\
\text { de joelhos, porém cada lutador } \\
\text { contaria com um colega que } \\
\text { faria o papel de auxiliar técnico, } \\
\text { cuja função seria observar os } \\
\text { procedimentos utilizados pelos } \\
\text { lutadores e, em momentos } \\
\text { específicos, rever situações com } \\
\text { seu colega, combinar ações e } \\
\text { estratégias. Num segundo } \\
\text { momento, abriu-se a } \\
\text { possibilidade de cada grupo } \\
\text { manejar regras e acordos. }\end{array}$ & $\begin{array}{l}\text { Com essa organização e direcionamento } \\
\text { dado à aula, continuou a participação } \\
\text { efetiva dos alunos, com um grau de } \\
\text { interesse, de contribuição e de decisão, } \\
\text { junto a seus colegas, aumentado. Essa } \\
\text { forma organizacional nessa turma } \\
\text { desencadeou grande motivação. Percebeu- } \\
\text { se de fato maior interação. No momento } \\
\text { em que se abriu para novos arranjos nos } \\
\text { acordos e regras, o grau de interação } \\
\text { aumentou ainda mais. Percebeu-se, a partir } \\
\text { de então, dois contra um, dois contra dois, } \\
\text { todos contra todos no grupo, e desafios de } \\
\text { grupo com grupo, o que rompeu quase que } \\
\text { totalmente com a situação inicial vivenciada } \\
\text { de pouca predisposição por parte de uns } \\
\text { interagirem com alguns colegas. }\end{array}$ \\
\hline
\end{tabular}

continua...

Movimento, Porto Alegre, v. 13, n. 03, p. 91-110, setembro/dezembro de 2007. 


\begin{tabular}{|l|l|l|}
\hline continuação. \\
\begin{tabular}{|c|l}
\hline 7 ạa \\
Avaliação das aulas pelos alunos e \\
auto-avaliação, conforme ficha \\
elaborada pelo professor.
\end{tabular} & $\begin{array}{l}\text { Os alunos deixaram transparecer, na } \\
\text { avaliação do conteúdo e das aulas, } \\
\text { que a expectativa e motivação nas } \\
\text { aulas foram mantidas em níveis ótimos } \\
\text { e, também, que reconheceram a } \\
\text { validade da nova experiência. Na auto- } \\
\text { avaliação, deixaram transparecer que } \\
\text { haviam compreendido a proposta de } \\
\text { criação coletiva e a necessidade de } \\
\text { autocontrole de suas ações e } \\
\text { emoções no desenvolvimento de suas } \\
\text { atividades, assim como reconheceram } \\
\text { atitudes e ou sentimentos particulares } \\
\text { de medo, vergonha, ansiedade e } \\
\text { coragem. }\end{array}$ \\
\hline
\end{tabular}

Quadro 2. Relato resumido da vivência realizada, acompanhado de considerações gerais a respeito de cada aula.

Não foram percebidos comportamentos violentos ou agressivos, nem física, nem verbalmente, no desenvolvimento de todas as aulas; ao contrário, percebeu-se um envolvimento constante nas tomadas de decisões e um zelo para o cumprimento dos acordos.

Essa constatação nos leva a compactuar com a posição de Olivier (2000), anteriormente referida. Os resultados obtidos, no nosso entendimento, relativizam o argumento da violência como sendo algo restritivo ao trato deste conteúdo por essa disciplina escolar. Entendemos também que fundamental é a maneira de conduzir a tematização deste conteúdo, o que vale também para o futebol e as demais manifestações da cultura corporal de movimento. Qualquer que seja o tema a ser abordado, se não for fundamentado e tratado pedagogicamente, corre o risco de gerar conflitos e situações hostis, o que confirma o entendimento esboçado por Parlebas apud Belbenoit (1974, p. 114-115) de que:

[...] o desporto [ou outro tema] não possui nenhuma virtude mágica. Ele não é em si nem socializante nem anti-socializante. É conforme: ele é aquilo que se fizer dele. A prática do judô ou do râguebi pode formar tanto patifes como homens perfeitos preocupados com o fair-play.

Movimento, Porto Alegre, v. 13, n. 03, p. 91-110, setembro/dezembro de 2007. 


\section{Artifos Orifinais Paulo do Nascimento e Luciano de Almeida}

\section{CONSIDERAÇÕES FINAIS}

A partir das experiências relatadas e analisadas, podemos afirmar que os dois fatores inicialmente diagnosticados como restritivos ao trato pedagógico do tema de lutas na Educação Física escolar podem realmente ser relativizados. Essa relativização e o conseqüente tratamento pedagógico deste tema, em nosso entender, estão atrelados ao delineamento de uma concepção específica de Educação Física por parte do professor e aos arranjos metodológicos coadunados com essa perspectiva, no caso deste estudo, a "cultura corporal de movimento".

Precisamos elaborar "novas" abordagens a partir de nossas experiências práticas, que, com certeza, irão nos remeter a novas questões, considerando cada realidade. Essas novas questões ou problemas não devem ser encarados como empecilhos, e sim como pontos de partida para re-estruturarmos nosso fazer pedagógico cotidiano, pois essa é uma condição normal, "natural", para quem adota uma postura de constante aprendizado e compreende o movimento eterno do conhecimento, que, por ser reconhecidamente de caráter provisório, está sempre passível de ser re-significado de acordo com as realidades, concepções e momentos históricos específicos.

The thematic of fights in the Physical Education
at School: restrictions and possibilities
Abstract: To the theme/content of fights, indicated
to be treated pedagogically by the curricular subject
of Physical Education at school, some restrictions
are shown. The challenge of the present work was
to carry out necessary thoughts about the theme as
well as effective interventions in the school context,
in order to confront them. It is understood that, with
these "unique" experiences, it was possible to consider
the impeding factors made available to the pedagogic
handling of this theme/content at school, and we
emphasize the importance for the teacher to have
clear to himself the theoretic perspective under which
he/she has to deal with contents and give up work
methodologies adjusted with the respective theory.
Keywords: Fight. Physical Education. Curriculum.

Movimento, Porto Alegre, v. 13, n. 03, p. 91-110, setembro/dezembro de 2007. 


\begin{abstract}
La tematización de las luchas en la Educación Física Escolar: restricciones e posibilidades Resúmen: Al tema de luchas, indicado para ser tratado pedagógicamente por la disciplina curricular de Educación Física en la escuela, se presentan algunas restricciones. El desafío de este trabajo fue realizar una necesaria reflexión sobre el tema, y efectivas intervenciones no contexto escolar, para compararlas. Entendemos que, con esas experiencias "singulares", fue posible relativizar "obstáculos" puestos para el trato pedagógico de ese tema/contenido en la escuela, y reforzamos la convicción de la importancia de el profesor tener clara para si la perspectiva teórica bajo la cual tratar los contenidos e lanzar mano de metodologías de trabajo sintonizadas con la respectiva teoría.

Palabras clave: Lucha. Educación Física. Currículo.
\end{abstract}

\title{
REFERÊNCIAS
}

ALMEIDA, Luciano de; FENSTERSEIFER, Paulo Evaldo. O que ensinar e aprender nas aulas de educação física na escola? Revista Digital, Buenos Aires, v. 11, n. 102, nov. 2006. Disponível em: <http://www.efdeportes.com/efd102/aulasef.htm>. Acesso em: 20 jan. 2007

BELBENOIT, Georges. O desporto na escola. Lisboa: Estampa, 1974.

BRASIL. Ministério da Educação e Cultura. Secretaria de Educação Fundamental. Parâmetros Curriculares Nacionais: Educação Física. Brasília: MEC/SEF, 1997.

DAOLIO, J. Educação Física Escolar: em busca da pluralidade. Revista Paulista de Educação Física, São Paulo, supl. 2, p. 40-42, 1996.

DARIDO, Suraya Cristina. Os conteúdos da educação física escolar: influências, tendências, dificuldades e possibilidades. Perspectivas em Educação Física Escolar, Niterói, v. 2, n. 1 (supl.), p. 5-25, 2001.

KUNZ, Elenor. Transformação didático-pedagógica do esporte. 4. ed. ljuí: UNIJUÍ, 2001.

MALDANER, Otavio Aloísio. A formação inicial e continuada de professores de química: professores/pesquisadores. ljuí: UNIJUÍ, 2000.

NASCIMENTO, Paulo R. B. A capoeira no contexto da escola e da Educação Física. 2005. Dissertação (Mestrado) - Faculdade de Pedagogia, Universidade Regional do Noroeste do Estado do Rio Grande do Sul, UNIJUÍ, ljuí, 2005.

Movimento, Porto Alegre, v. 13, n. 03, p. 91-110, setembro/dezembro de 2007. 
110 Astifos Orifinais Paulo do Nascimento e Luciano de Almeida

NASCIMENTO, Paulo R. B. Apostila da disciplina de Metodologia do Ensino de lutas, 2006. (Mímeo).

NASCIMENTO, Paulo R. B. Sistematização do tema/conteúdo de lutas para a Educação Física escolar. 2007. (Mímeo).

OLIVIER, Jean-Claude. Das brigas aos jogos com regras: enfrentando a indisciplina na escola. Porto Alegre: Artes Médicas Sul, 2000.

SBÓRQUIA, S. P.; GALHARDO, J. S. P. A dança no contexto da Educação Física. ljuí: Ed. UNIJUÍ, 2006.

THIOLLENT, Michel. Metodologia da pesquisa-ação. São Paulo: Cortez, 1988.

Movimento, Porto Alegre, v. 13, n. 03, p. 91-110, setembro/dezembro de 2007. 